\title{
The different flavours of research collaboration: a case study of their influence on university excellence in four world regions
}

\author{
Maria Benavent-Pérez ${ }^{1}$, Juan Gorraiz ${ }^{2}$, Christian Gumpenberger ${ }^{2}$ \\ and Félix de Moya-Anegón ${ }^{1}$
}

${ }^{1}$ maria.benavent@cchs.csic.es, felix.moya@scimago.es

CSIC, Institute of Public Goods and Policies, SCImago Research Group, Albasanz 26-28, 28037 Madrid, Spain

2 juan.gorraiz@univie.ac.at, christian.gumpenberger@univie.ac.at

University of Vienna, Vienna University Library, Bibliometrics Department, Boltzmanngasse 5, A-1090 Vienna, Austria

\begin{abstract}
This study on research collaboration $(R C)$ is an attempt to estimate the degree of internationalization of academic institutions and regions. Furthermore potential influences of RC on excellence initiatives of modern universities are investigated relying on source data obtained from SCImago Institutions Rankings (SIR).

A positive correlation exists between the degree of collaboration and the normalized impact. However, in contrast to output the normalized impact increase progression is non-linear and fluctuating.

Differences occur regarding output volume and normalized impact at geographical region level for the leading universities. Different patterns of the Brute Force distribution for each collaboration type were are also observed at region level as well as at subject area level.

A continuously reduced percentage of the domestic (non-collaboration) academic output is a world trend, whereas a steady increase of "international + national" collaboration is observed globally, however, less distinctive in Asia than in the other regions.

The impact of Latin American papers originating from domestic production as well as from national collaboration remains considerably below world average values.
\end{abstract}

Keywords Research collaboration - Citation Impact - Excellence universities - Geographical regions - Subject areas

\section{Introduction}

Within the last decades knowledge production underwent radical changes. Research collaboration (RC) has become a necessity due to the enormous pressure scientists, institutions or even countries face in their daily struggles to meet the required publication output requirements. Thus the number of internationally co-authored papers is abruptly increasing, and an intensification of RC is reported at all aggregation levels (Narin et al. 1991; Katz and Martin, 1997; Katz and Hicks 1997; Glänzel et al., 1999; Glänzel, 2001). However, differences still exist among research fields regarding volume and impact of collaboration (Glänzel and Schubert, 2001). There is an increase of international scientific collaboration (ISC) in the emergent disciplines, where knowledge sharing needs to be most efficient (Heinze and Kuhlmann, 2008).

Several studies have also pointed out that multiple authorship produces an increase in citations as a positive side effect of RC (Leimu and Koricheva, 2005; Hsu and Huang, 2011; Hsiang Liao, 2011). Other findings only suggest a weak correlation between international papers and "highly-cited papers" except for small countries (Van Leuwen and Tijssen 2007; Glänzel and Schubert, 2001; Persson, 2010). This indicates that one should be cautious about extrapolating findings from one country to another (Glänzel et al., 1999), and even from one region to another region (Levitt and Thelwall, 2010).

Beyond doubt, influence on research impact certainly depends on the type of collaboration (Sooryamoorthy, 2009), however, not all types of collaboration have the same effect on research impact in terms of citations (Bordons et al., 1996; Lee et al., 2001; Persson et al., 2004; Gazni and Didegah, 2011; Gorraiz et al., 2011). 
Our study on RC is an attempt to estimate the degree of internationalization of academic institutions and regions. Furthermore potential influences of RC on excellence initiatives of modern universities shall be investigated.

This paper is organised as follows: first, the objectives and the underlying questions to be addressed are described. Second, the sources, the units of analysis and the indicators used in this study are specified. Third, the results are presented. Finally, the findings are summarized and directions for future research are concluded.

\section{Objectives}

Our study aims to analyse the effect of different types of collaboration (international, international + national, national, or none) on the citation impact of the research output from four selected geographical regions. Each region is represented by its ten most excellent universities.

The underlying questions are:

1) What are the proportions of the different collaboration types?

2) What is the estimated amount and impact of papers without collaboration (domestic)?

3) What is the trend in the different types of collaboration?

4) Does this trend differ from region to region?

5) Can evident discrepancies be observed across the six selected subject areas?

6) Are the degrees of collaboration and impact somehow correlated at the analysed universities?

\section{Methodology}

\section{Source data}

This analysis relies on source data obtained from SCImago Institutions Rankings (SIR). SCImago Institutions Rankings (SIR) is a science evaluation resource to assess universities and researchfocused institutions worldwide, based on Scopus (Elsevier B.V.) data.

\section{Units of Analysis: Regions, Excellence Universities and Subject Areas}

The focus of the study is Latin America (incl. the Caribbean countries). Results are compared with the two leading regions, Northern America and Western Europe. Furthermore, the Asiatic Region has been included due to its "research emergence" character for complementary reasons.

"Excellence" Universities* were determined according to the following selection criteria:

- in a first step the 50 most productive (regarding research output) universities were selected per geographical region

- in a second step the top 10 universities were determined according to the normalized impact

Almost 1 million $(929.353)^{1}$ publications were retrieved. Figure 1 shows the regional distribution of the data retrieved for this study.

\footnotetext{
${ }^{1}$ This number represents the sum of all publications calculated in SCImago Institutions Rankings (SIR) from each university's contribution and does not consider any overlaps originating from joint publications.
} 


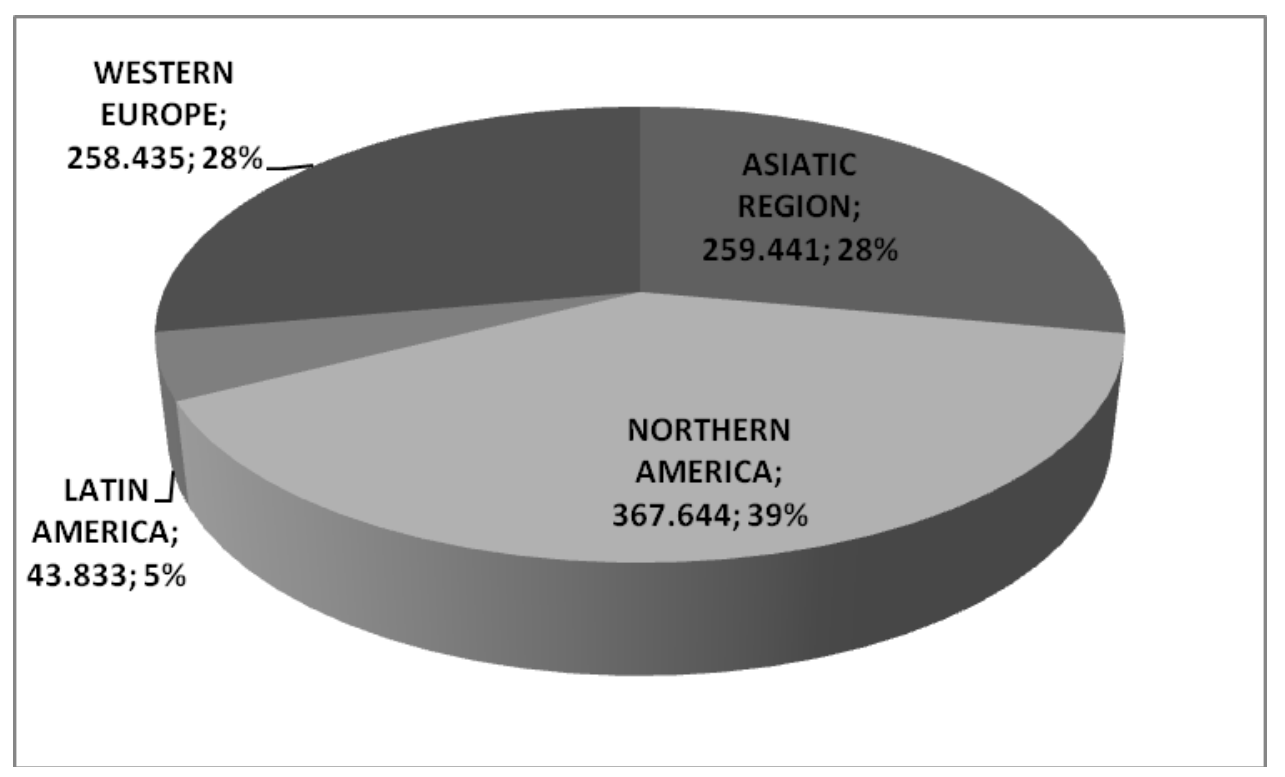

Fig. 1 Regional distribution of the data

Following 6 subject areas (as defined in Scopus) were chosen in order to represent all parts of the global scientific spectrum:

- $\quad$ Arts and Humanities (A\&H)

- Social Sciences (SOC)

- Mathematics (MATH)

- Psychology (PSY)

- Immunology and Microbiology (IMM)

- Physics and Astronomy (PHY)

\section{Indicators}

For each university (all fields + the 6 selected subject fields) following indicators were calculated for the period 2003-2008 (6 years):

\section{1) Output:}

Number of publications (research articles, proceedings papers \& review articles)

2) Percentage of research collaboration per type:

Different types of collaboration, i.e. "international", "international + national", "national", and "none" will be determined. Joint publications as a result of cooperation between institutional researchers and researchers from other countries are regarded as international publications. Those originating from collaboration between institutional researchers, researchers from other countries and researchers from the same country are assumed to be "international + national" publications. National publications are only authored by researchers from the same country but from different institutions. Finally, publications only co-authored by researchers from the same university can be regarded as publications without collaboration (domestic).

\section{3) Impact}

Normalized Impact scores indicate the scientific impact that institutions have on the scientific community. In order to obtain a fair impact measurement, its calculation removes any influences caused by institutional size and research profile. Thus normalization allows for research performance comparisons. Normalized Impact values show the ratio of the average institutional scientific impact to the world average impact of publications of the same time frame, document type and subject area. The values are expressed in percentages and show the relationship of the institution's average impact to the world average, which is 1, i.e. a score of 0.8 means that the institution is cited $20 \%$ below world average and 1.3 means that the institution is cited $30 \%$ above world average (SCImago, 2009). 


\section{4) Brute Force}

Following the definition used in the Leiden Ranking of Universities, introduced by the Centre for Science and Technology Studies (CWTS) of the Leiden University (Leiden Ranking, 2011), the Brute Force is a size-dependent impact indicator, obtained by the multiplication of the number of citable publications (articles, reviews and proceedings papers) with field-normalized average impact. It therefore balances productivity and impact. In this study an equivalent of the brute force has been calculated by multiplying the number of citable publications with SciMago Field-normalized average impact.

All searches in the source data were carried out between February and March 2011. The indicators obtained from the SIR were collected using the version available in that time frame.

\section{Statistics}

The following statistical tests were used to identify the differences between the collaboration types for the four regions according to their collaboration degree:

- the ANOVA (analysis of variance) test using either the region variable or subject area variable as a factor $F$, it shows similarities and differences.

- the Kruskal-Wallis $\mathrm{H}$ test (Kruskal and Wallis, 1952) detects if $n$ data groups either belong or not belong to the same population. Since it is a non-parametric method, the Kruskal-Wallis test does not assume a normally distributed population, which makes it ideal for scientometric distributions (Ortega, 2011).

- finally, the Bonferroni Correction, post hoc test, used after the Kruskal-Wallis to address the problem of multiple comparisons.

\section{Visualisation techniques}

Multidimensional scaling (MDS), a set of statistical techniques, was used for exploring similarities or dissimilarities in data at university level.

The statistical analysis was based on SPSS Statistics 19.

\section{Results}

\section{Different types of research collaboration and normalized citation impact}

Figure 2 shows the percentage of the volume of each collaboration type and the normalized impact scores for all the universities considered in this analysis (40 universities belonging to 4 different geographic regions). "International + national" collaboration has the lowest volume but shows the highest normalized impact. On the other hand, publications "without collaboration" have the highest volume but the lowest normalized impact.

Thus, the highest degree of collaboration shows the biggest impact (collaboration and impact correlate positively). 


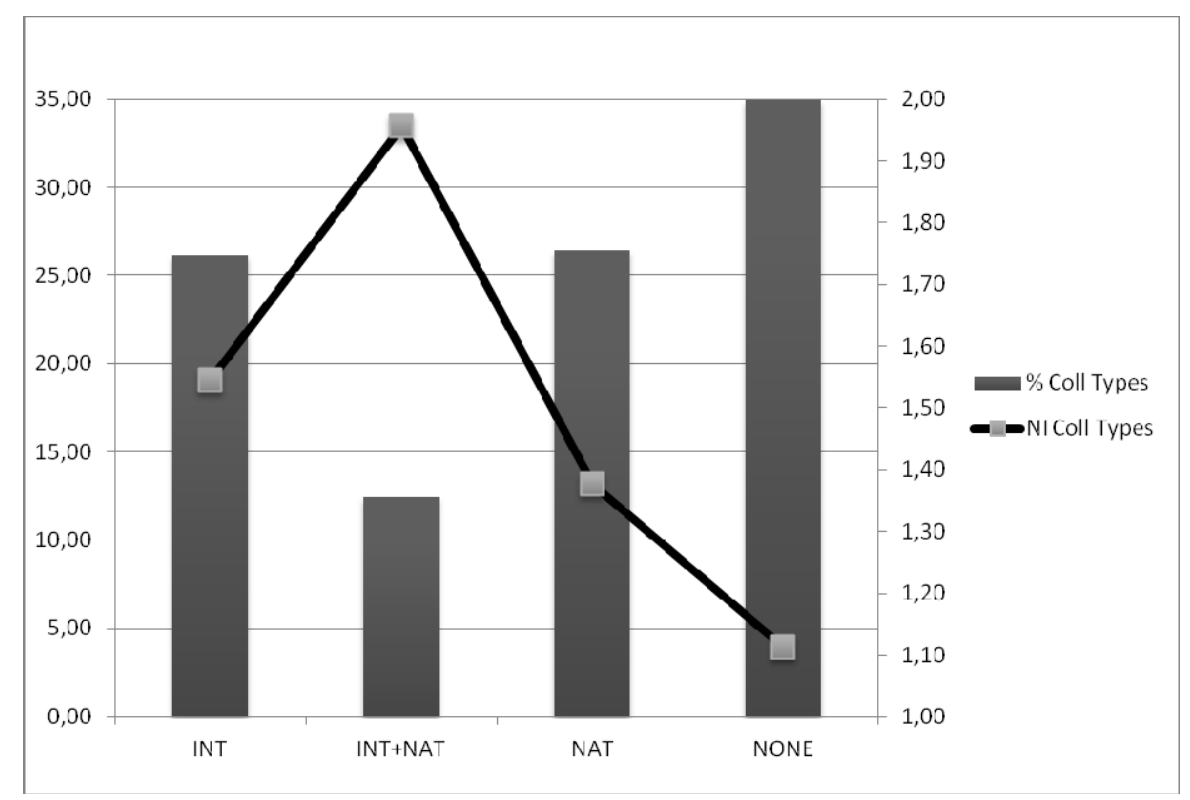

Fig. 2 Distribution of research collaboration types and normalized citation impact

\section{Similarities and dissimilarities between universities: output and impact of research collaboration}

The following figures represent two different MDS (Multidimensional Scalings), the first one depicts the output (volume) (Fig. 3) of each collaboration type, and the second one shows the normalized impact (Fig. 4). Universities are clustered corresponding to their degree of similarity based on the indicators used, volume and impact of each collaboration type. The clusters are predominantly composed of universities belonging to the same geographic region (distinguishable colours for each region), because they have more features in common at regional than at international level.

Interesting outliers can be identified regarding output volume in Fig. 3:

- Harvard University, Universidad Nacional de Mar de Plata and Universidad Federal de Pelotas (see upper right quadrant) all show an atypically (extremly) high volume of national collaboration

- Furthermore Harvard University has the smallest percentage of output without collaboration of (17\%). All other North American universities in this analysis show values double as high.

- Korea Advanced Institute of Science and Technology (see lower right quadrant) has the highest volume of non-collaboration and the second lowest of "national + international" collaboration papers.

- Nanyang Technological University (see lower left quadrant) is similar to the Korean Advanced Institute of Science and Technology regarding the output of non-collaboration and "national + international" collaboration papers, however, the percentage of "international" collaboration is much higher.

- Universidad de Puerto Rico, Universidad Republica and City University of HongKong (see left part of Fig. 3) all have high percentages of both "international" and "non-collaboration" papers.

In contrast to output the universities show a higher similarity regarding normalized impact (see Fig. 4) with a concentrated cluster in the central part of the chart. However, clear differences (patterns) for each geographical region obviously exist. The left part represents universities of regions with lower impact values for all types of collaboration (Latin America, Asiatic Region), whereas the ones with the higher impact values (Western Europe and Northern America) can be found on the right side. The Universidad Federal de Pelotas and Erasmus University are outliers having a higher impact considering their international collaboration.

The exact values can be looked up for each university in Annex 2. 


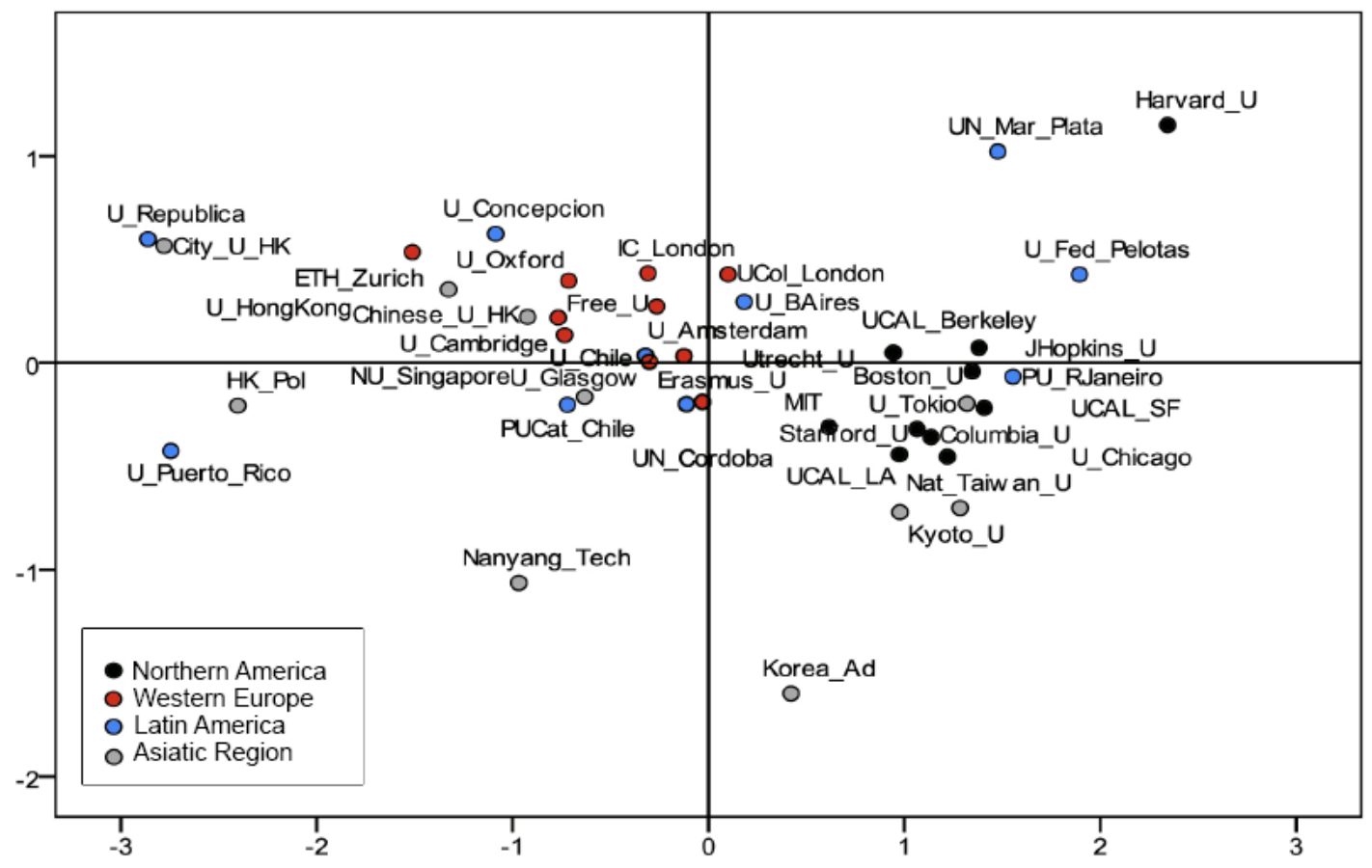

Fig. 3 Multidimensional Scaling (MDS) for output in collaboration types

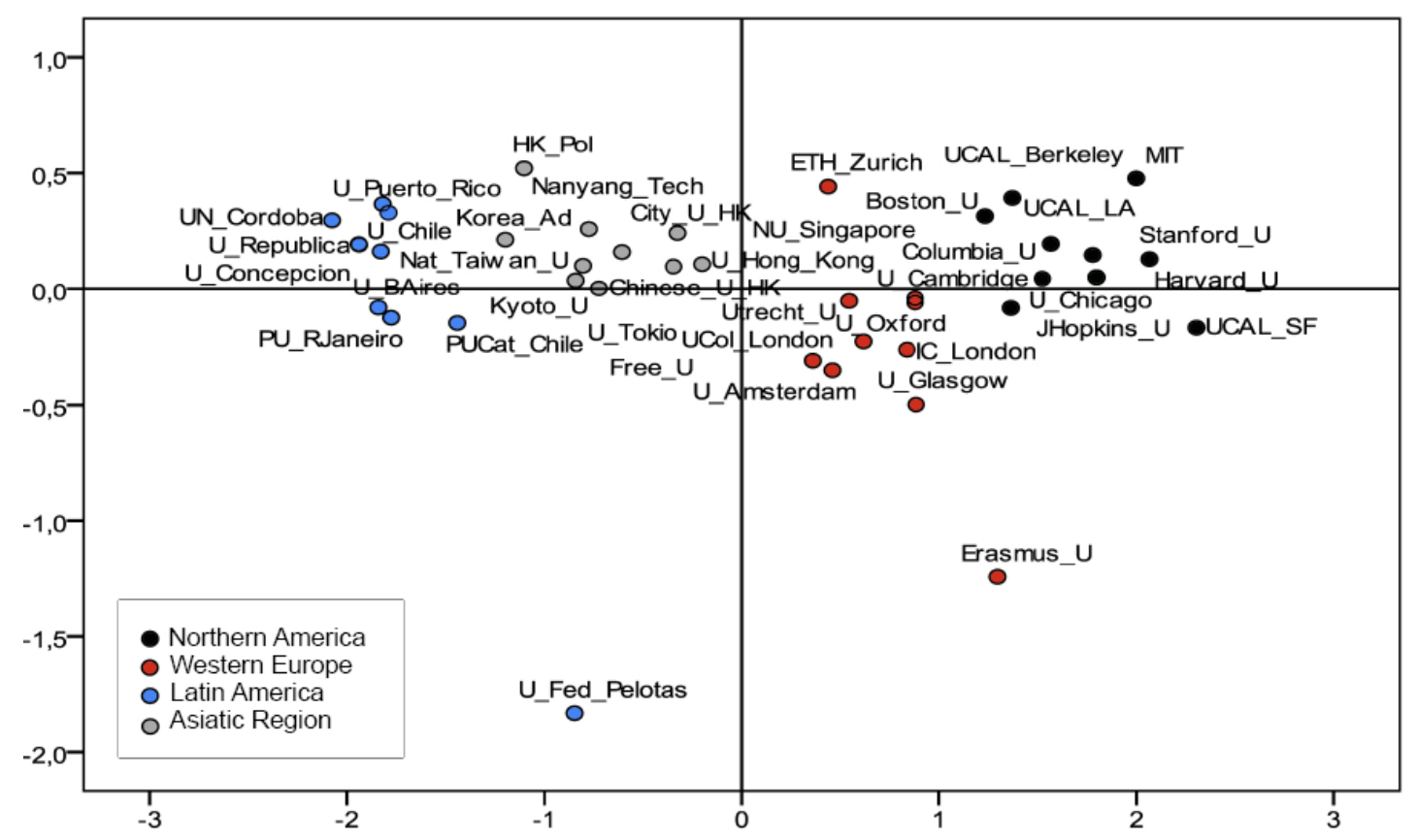

Fig. 4 Multidimensional Scaling (MDS) for Normalized citation by collaboration types

Do the collaboration and impact patterns differ from one region to another?

Fig. $5 \mathrm{a}$ and $5 \mathrm{~b}$ shows the timeline of output and normalized impact for each collaboration type between 2003 and 2008 in all different regions.

General trends are readily identifiable for all regions and for each collaboration type regarding output (see Fig. 5a). All regions show an increase of "national + international" collaboration and a decrease of research output without collaboration. International collaboration also received a boost in three 
regions, especially in the Asiatic one. This is not true for Latin America, where national collaboration grows constantly (in contrast to international collaboration) compared to the other regions.

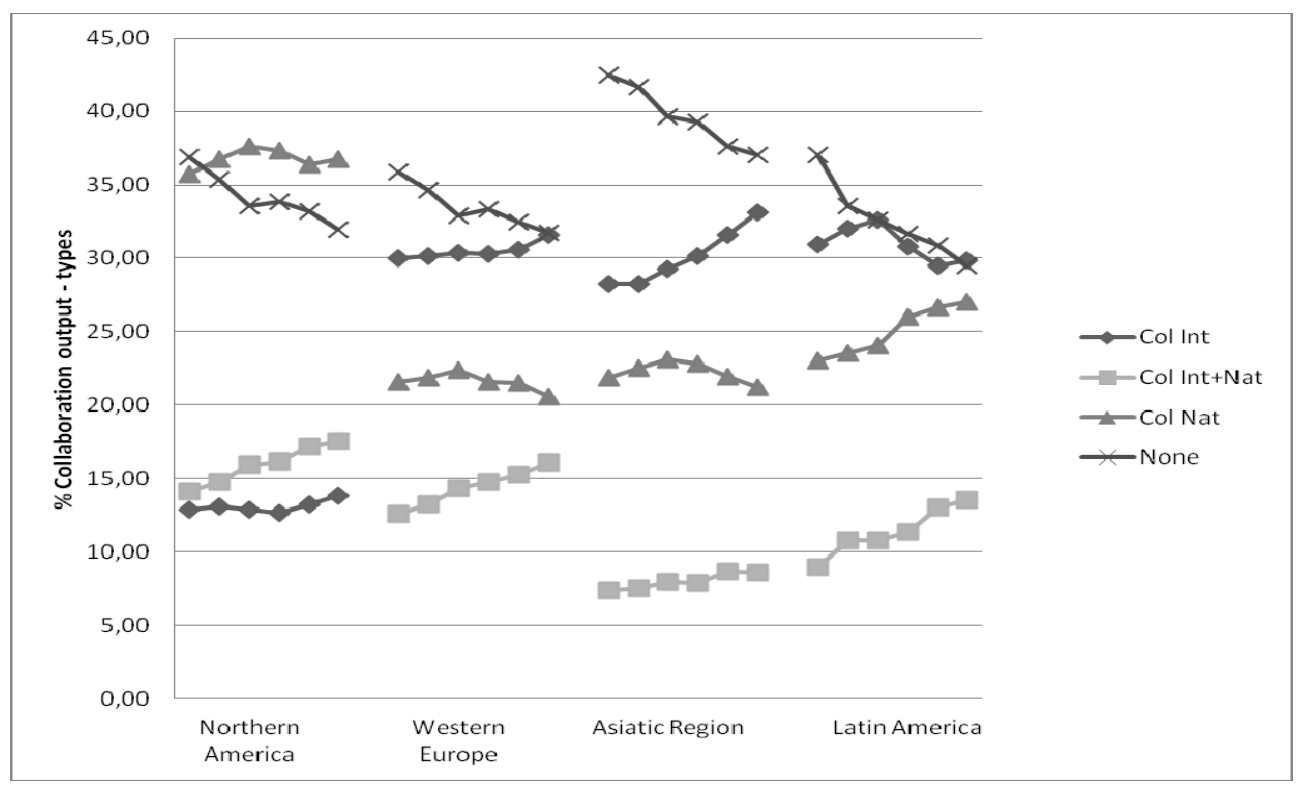

Fig. 5a Trend of output\% per RC types by geographical regions

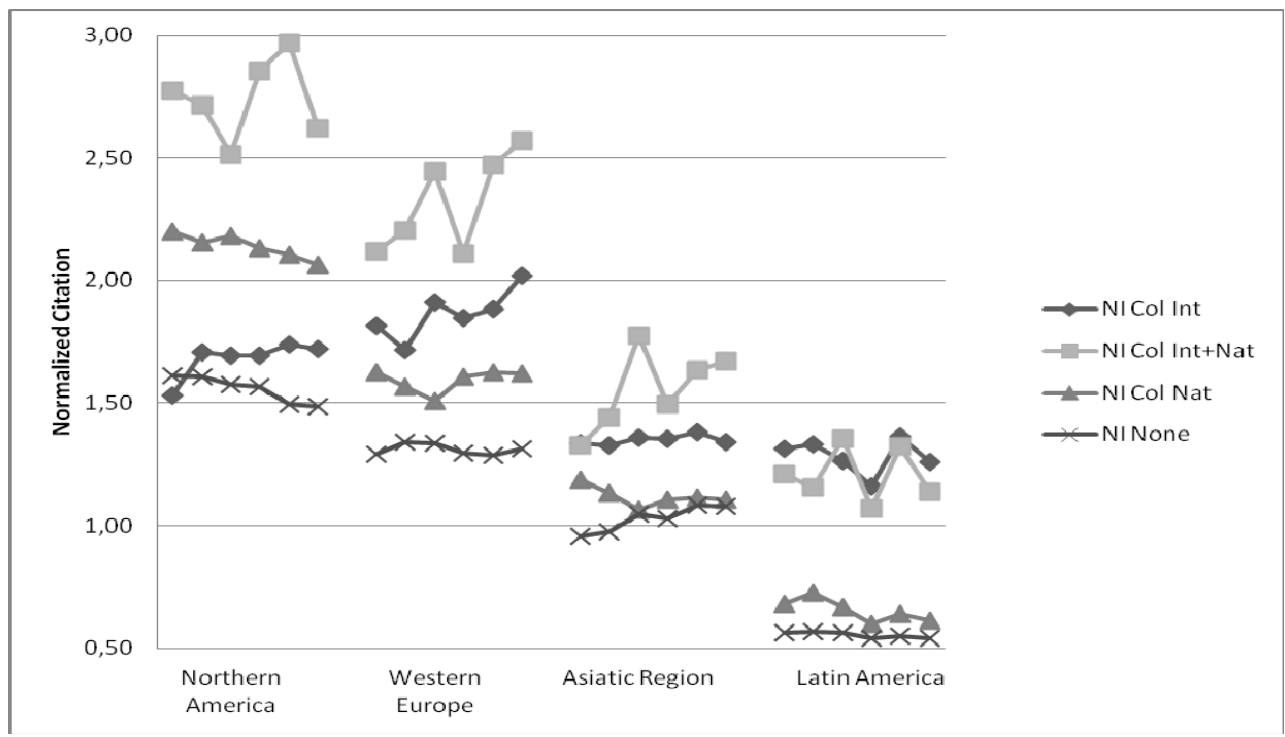

Fig. $\mathbf{5 b}$ Trend of Normalized Citation per RC types by geographical regions

Regarding normalized impact (see Fig. 5b) "national + international" collaboration is the most important collaboration type in all regions. Northern America is the only region where international collaboration is outweighed by national collaboration. Normalized impact is lowest for all collaboration types in Latin America. Whenever international collaboration is absent, Latin America remains below the world average.

Distribution of research collaboration types and normalized citation impact in 6 subject fields

A comparative analysis of six selected subject areas shows that the amount of publications without collaboration is extremely high in Arts \& Humanities (71.76\%), followed by Social Sciences $(54.63 \%)$ and Psychology (37.16\%). International collaboration reaches their maximum values in Mathematics 
and Physics with $35.33 \%$ and $33.49 \%$ respectively, whereas national collaboration is more common in Immunology (31.33\%). For details refer to Fig. $6 a$.

Considering the normalized impact, publications with national + international collaboration score highly in the fields of Physics, Immunology, Mathematics, and even in the Social Sciences (see Figure 6b). International collaboration is most influential in Psychology, whereas the same is true for output of national collaboration in Arts \& Humanities. Overall the documents originating from research without any collaboration have lower impact than those of all other collaboration types for all the areas analyzed.

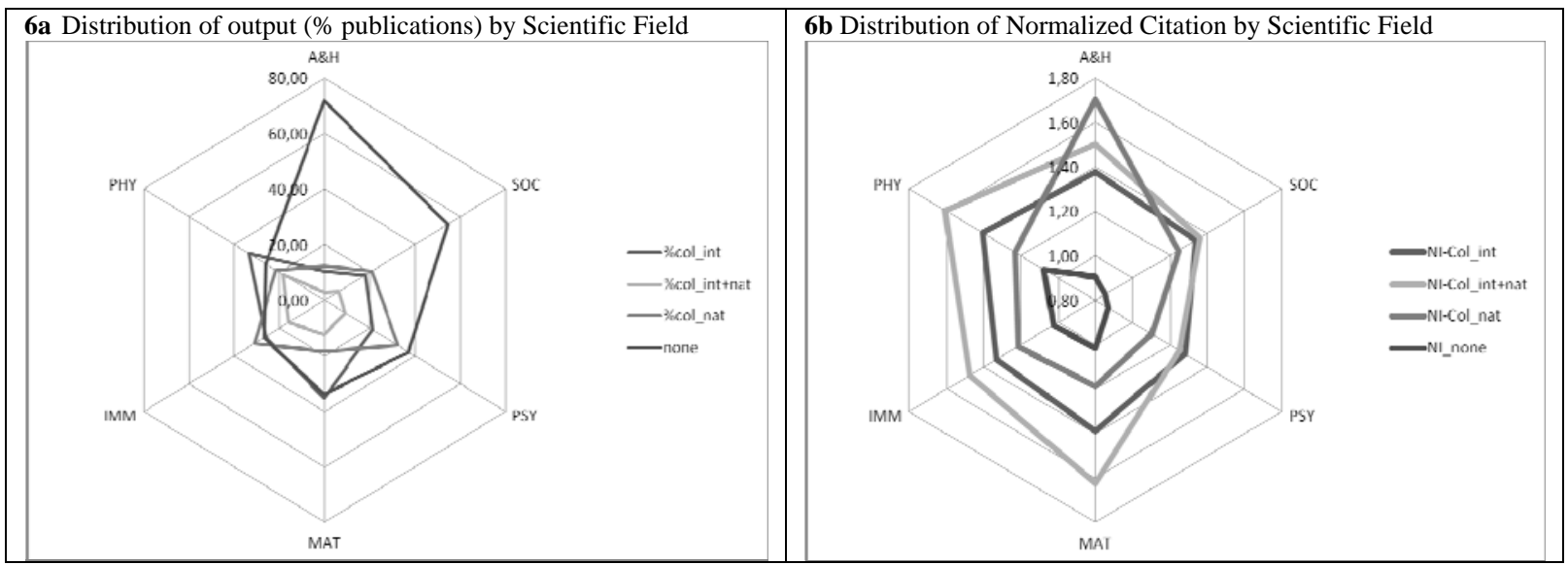

Fig. 6 Distribution of output and Normalized Citation per RC by Scientific Field

\section{Brute Force}

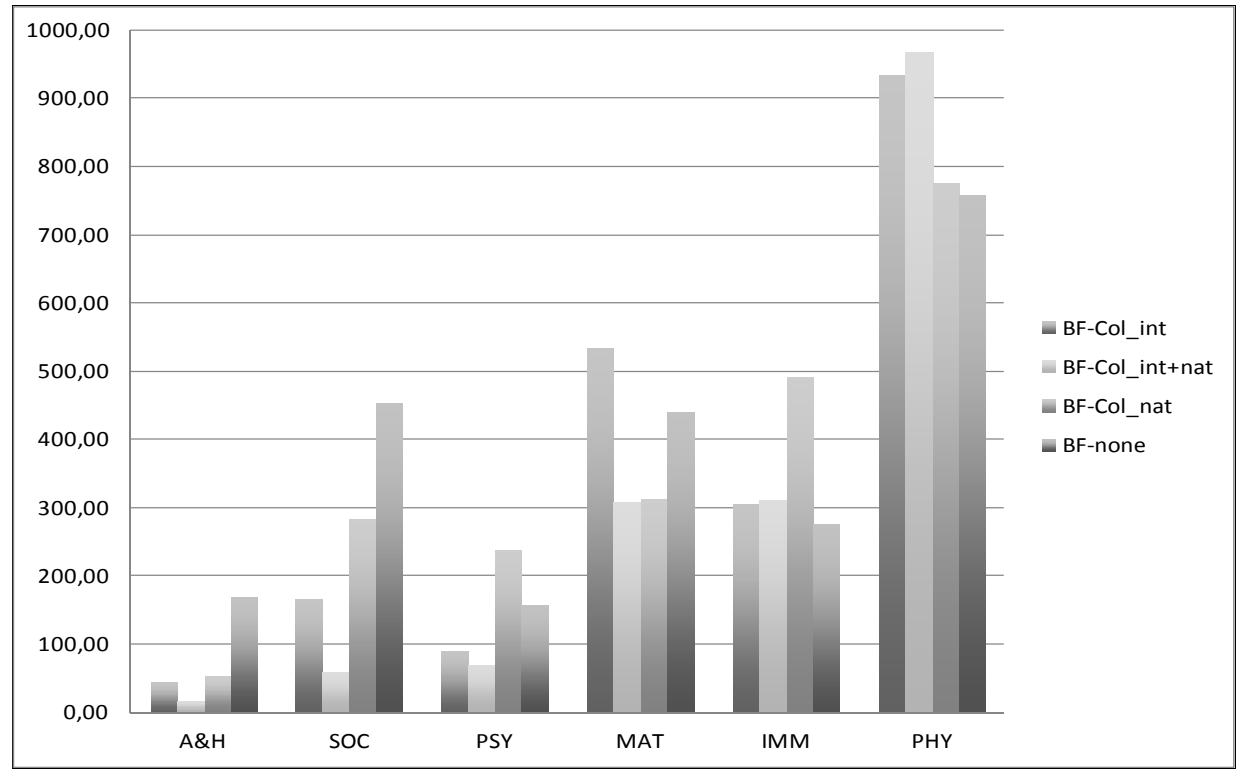

Fig. 7 Distribution of the Brute Force by Scientific Field according to the collaboration type

Figure 7 depicts the distribution of the annual mean Brute Force for the six considered areas. Each area obviously shows its very own characteristic pattern. The differences are most evident for Physics" and "Social Sciences“"2.

Therefore trends for both fields were further analyzed in more detail for each region.

\footnotetext{
2 "Arts \& Humanities" are even more different, however, the number of publications is too low in this field which makes further comparisons less relevant
} 


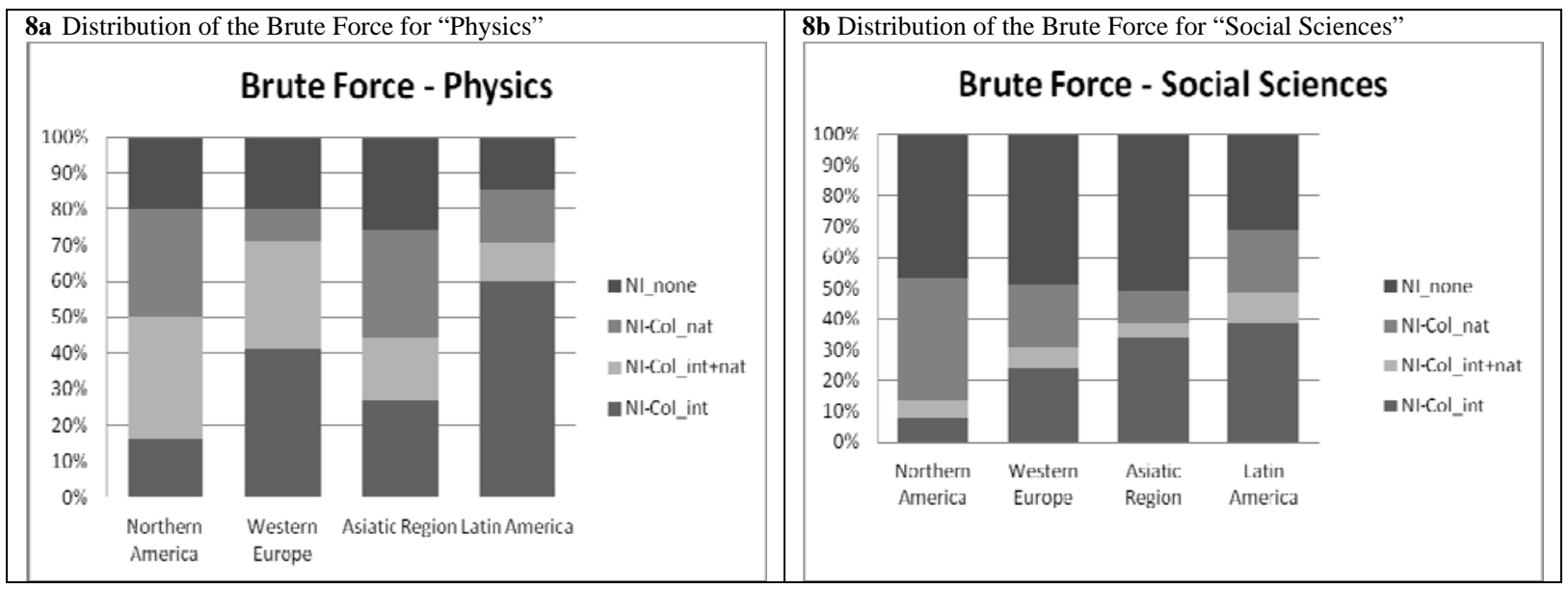

Fig. 8 Distribution of the Brute Force by region according to the collaboration type for two subject fields (clustered-stacked column chart)

In Physics (see Fig. 8a) non-collaborative publications account only for $20 \%$ of the Brute Force for all regions except for Latin America (approx. 15\%). The biggest share of national collaboration comes from Northern America and the Asiatic Region. „International + national“ collaboration represent the biggest contribution to the Brute Force in Northern America (approx. 35\%) and in Western Europe $(30 \%)$, whereas the values for the Asiatic Region and Latin America are much lower with $15 \%$ resp. $10 \%$.

In "Social Sciences"(Fig. 8b) the situation is in stark contrast to Physics. Here the non-collaborative publications present the major share (almost 50\%) of the Brute Force in all regions except Latin America (still 30\%). In Social Sciences the percentage of "international + national" collaboration is generally low, and the contribution of international collaboration to the Brute Force becomes more important the lesser developed the region is.

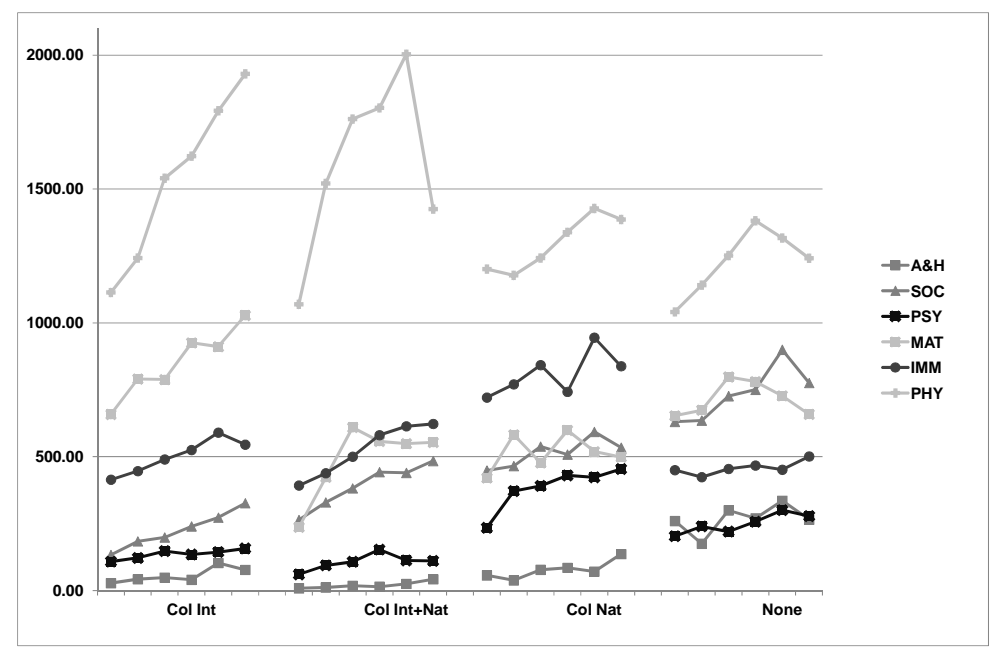

Fig. 9 Trend of Brute Force per research fields by RC types

Figure 9 shows the time line of the Brute Force between 2003 and 2008 for each subject area according to the collaboration type. In Physics and Mathematics there is an increase in the first years followed by a decline in the last years for each collaboration type except for the international one. In 
Social Sciences one can see a constant increase for all collaboration types, whereas in Arts \& Humanities as well as in Psychology hardly any differences can be found.

Looking at the Brute Force percentages for each collaboration type in Physics as well as in Social Sciences these tend to show no major alterations along the analysed years (see Fig. 10).

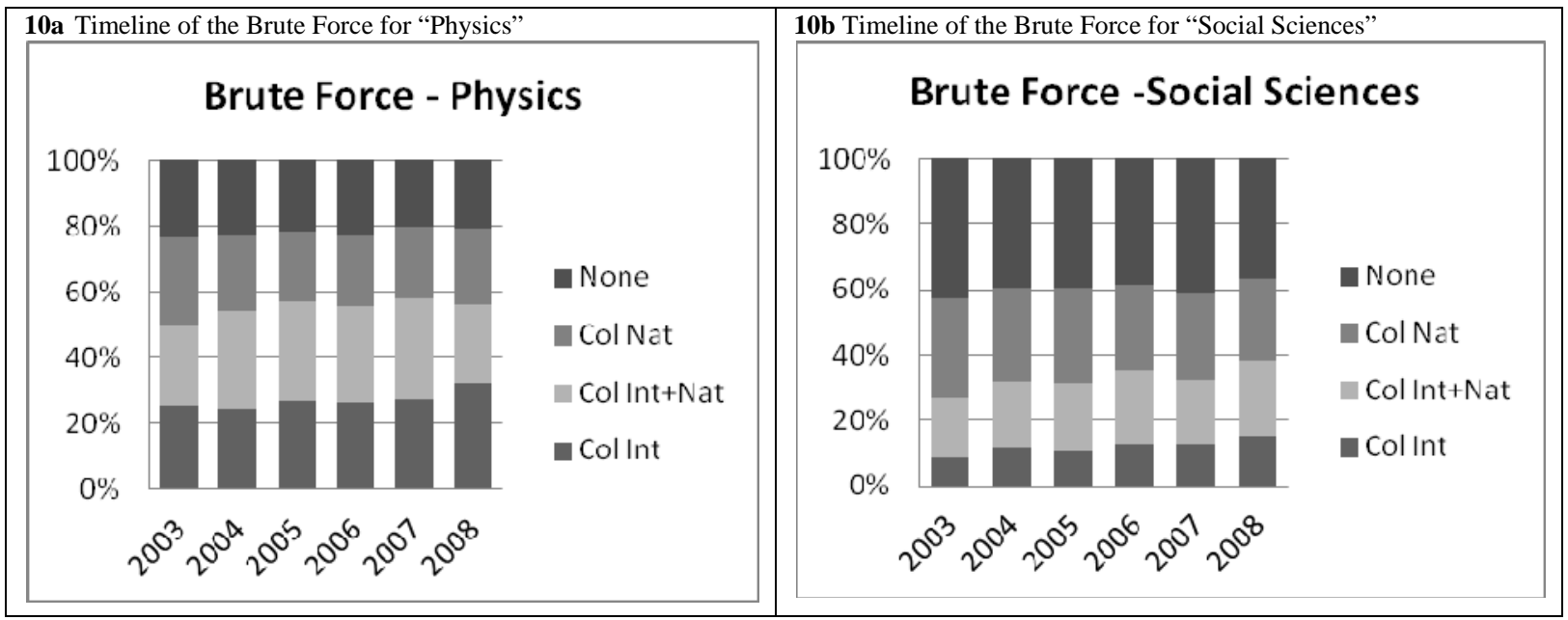

Fig. 10 Timeline of the Brute Force according to the collaboration type for two subject fields (clusteredstacked column chart)

\section{Differences among regions and subject areas}

Different patterns have already been recognized for each geographic region and subject category and were further explored by statistical tests analysing established pairs.

Considering first the geographical region as factor $\mathrm{F}$, and applying the One Factor Anova test and of Kruskall-Walis $\mathrm{H}$ test, the $\mathrm{p}$-value related to the value of $\mathrm{F}$ is less than $\alpha=0.05$ (significance level for entire test series) for almost all the variables. Considerable differences occur between the geographical regions regarding output and normalized impact for all collaboration types. Only for documents originating from national collaboration $(p=0.010$ in the Anova test and $p=0.013$ in the Kruskall-Walis $\mathrm{H}$ test) and for documents without collaboration ( $p=0.045$ in Anova and $p=0.052$ in Kruskall-Walis) significant regional similarities could be identified.

In order to identify considerable differences between regions and to find homogeneous groups, the Bonferroni correction was applied. Table 1 shows the normalized citation values for the different groups (clusters) that can be distinguished according to the four different collaboration types. Regarding international collaboration an overlap of the clusters was observed. Thus, the Asiatic Region (clusters A and B) has common characteristics with Latin America (via cluster A) and Northern America (via cluster B), whereas similarities occur between Northern America and Western Europe via cluster $\mathrm{C}$. All the other collaboration types lack such an overlap with each region forming an own cluster.

Table 1 Regional Normalized Citation. Differences for each collaboration type (Bonferroni Correction Test)

a) Normalized Citation for International Collaboration

\begin{tabular}{lllll} 
Region & Mean & \multicolumn{3}{c}{ Cluster } \\
Asiatic Region & 1.351 A & B & \\
Latin America & 1.283 & A & & \\
Northern America & 1.682 & B & C \\
Western Europe & 1.866 & & C
\end{tabular}

b) Normalized Citation for International + National Collaboration

\begin{tabular}{llllll} 
Region & Mean & \multicolumn{3}{c}{ Cluster } & \\
Asiatic Region & 1.557 & A & & & \\
Latin America & 1.208 & B & & \\
Northern America & 2.741 & & C & \\
Western Europe & 2.321 & & & D \\
\hline
\end{tabular}




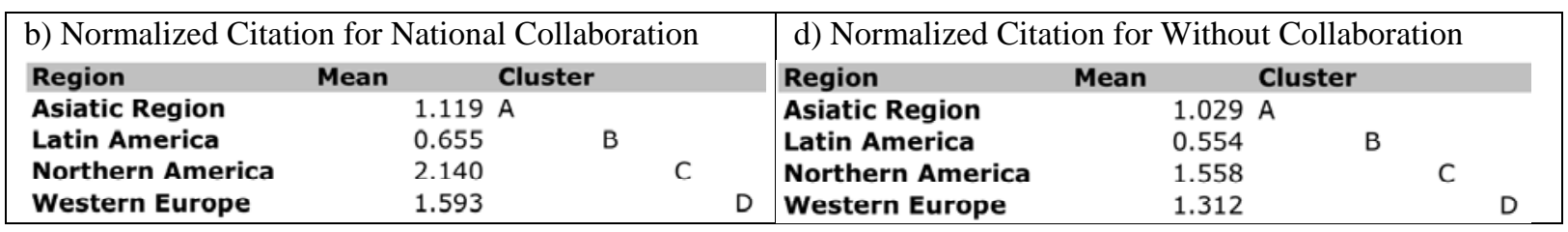

Applying the same methodology, both statistical tests were run with the factor 'subject area'. All the variables related to the percentage of documents for each collaboration type show considerable differences in both Anova and Kruskall-Walis $\mathrm{H}$. Quite different are the results for all the variables related to the normalized impact for each collaboration type, where the $p$-value related to the value $F$ is much higher than $\alpha=0.05$ for all the variables. Only the Normalized Impact for the national collaboration is low $(p=0.023)$.

Table 2 shows the mean output (percentages) of the subject areas for the different groups (clusters) that can be distinguished according to the four different collaboration types $(p<0.05)$. Regarding international collaboration there is an overlap of the clusters A and C, i.e. a significant similarity between A\&H and SOC was observed. Furthermore similarities occur between SOC, IMM and PSY (overlap of clusters B and C).

In general, A\&H and SOC show common characteristics for all types of collaboration except "without" collaboration. Mathematics is related to SOC except whenever international collaboration occurs or to IMM and PSY for the other collaboration types.

PHYS, IMM and PSY show inconsistent clustering patterns.

Table 2 Differences between subject areas for each research collaboration type (Bonferroni Correction Test)

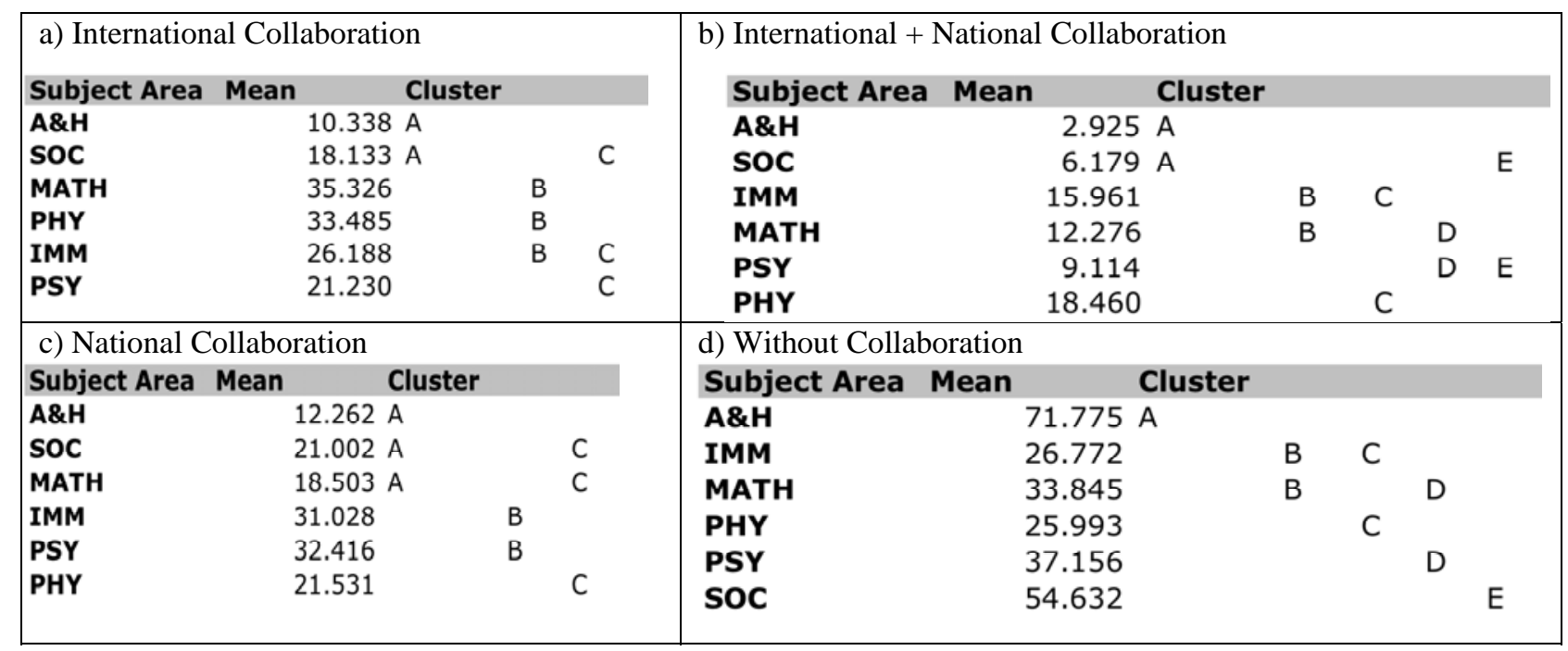

\section{Conclusions}

- $\quad$ There is a positive correlation between the degree of collaboration and the normalized impact (the more collaborators $\rightarrow$ the more impact; and vice versa). However, in contrast to output the normalized impact increase progression is non-linear and fluctuating.

- Differences occur regarding output volume and normalized impact at geographical region level for the leading universities.

The Asiatic Region and Latin America have lower normalized impact than Northern America and Western Europe. However, considering the percentage of output, these regions have the biggest amount of international collaboration. Few regional outliers could be observed.

- Without surprise National collaboration in Northern America plays a different role in comparison to the other regions. North-American partners are obviously perceived as more 
"interesting" than international ones, a phenomenon corroborated by the fact that national collaboration shows a much higher impact than pure international collaboration. However, large projects with national and international collaborators result in considerable impact gains.

- Harvard University, one of the most prestigious universities in the world, is outstanding with an extremely low percentage of publications without collaboration $(<15 \%)$. This trend is not observed for the other top US universities, however, a continuously reduced percentage of the domestic (non-collaboration) academic output is a world trend.

- A steady increase of "international + national" collaboration is observed globally, however, less distinctive in Asia than in the other regions.

- Latin American papers originating from domestic production as well as from national collaboration have - in contrast to the ones from the Asiatic Region - a very low impact which remains considerably below world average values. Further research regarding the causes is needed, e.g. taking into account socio-economic factors (as pointed out by several authors) or database coverage bias.

- Brute Force analysis is a valuable complement to balance productivity and impact. It allows the detection of patterns at subject area level as well as at regional level.

- Looking at all universities in all regions studied in this analysis, A\&H as well as SOC are the subject areas with the most "non-collaboration" output. Nevertheless the minority of collaboration papers result in normalized impact values comparable to the other analyzed subject areas. A\&H national collaboration papers even produce the highest normalized impact in all fields.

In conclusion, relations between the degree of collaboration and impact are undeniable. Significant differences between the four analysed regions regarding output and impact patterns were observed.

At the same time it was possible to determine a group of subject areas presenting similar patterns concerning their collaboration degree.

Nevertheless the authors are especially aware of two restrictions concerning this study. One is the bias concerning the database coverage, which most likely discriminates Latin America against the other analysed regions. Secondly, the USA represent a huge nation that is obviously difficult to compare to other countries at national level, particularly small countries in Europe. Here it would be more meaningful to contrast the USA with e.g. the whole EU (European Union).

Therefore further studies are planned to tackle these issues.

\section{References}

Bordons, M.; Gómez, I., Fernández, M.T., Zulueta, M.A. and Mendez, A. (1996). Local, domestic and international scientific collaboration in biomedical research. Scientometrics, 37(2), 279-295.

Gazni, A. and Didegah, F. (2011). Investigating different types of research collaboration and citation impact: a case study of Harvard University's publication. Scientometrics, doi: 10,1007/s11192011-0343-8

Glänzel, W., Schubert, A., Czerwon, HJ. (1999). A bibliometric analysis of international scientific cooperation of the European Union (1985-1995). Scientometrics, 45 (2): 185-202.

Glänzel, W. (2001). National characteristics in international scientific co-authorship. Scientometrics, 51(1), 69-115.

Glänzel, W. and Schubert, A. (2001). Double effort=double impact? A critical view at international coauthorship in chemistry. Scientometrics, 50(2), 199-214.

Gorraiz, J., Reimann, R. \& Gumpenberger, C. (2011). The Importance of Bilateral and Multilateral Differentiation in the Assessment of International Collaboration - a case study for Austria and six 
countries. Proceedings of the ISSI 2011 Conference, Durban, South Africa, 04-07 July. Vol. 1, 236-248.

Heinze, T. \& Kuhlmann, S. (2008). Across institutional boundaries? Research collaboration in German public sector nanoscience. Research Policy, (37), 888-899.

Hsu, J. and Huang, D. (2011). Correlation between impact and collaboration. Scientometrics, 86(2), 317-324. doi: 10.1007/s11192-010-0265-x

Katz, J.S., \& Hicks, D. (1997, June 16-19). How much is a collaboration worth? A calibrated bibliometric model. Scientometrics, 40(3), 541-554.

Katz, J.S. \& Martin, B.R. (1997). What's research collaboration? Research Policy, 26(1), 1-18.

Lee, K., Brownstein, JS, Mills, RG, Kohane, IS (2010). Does Collocation Inform the Impact of Collaboration? PLoS ONE, 5, 12, e14279,

Leiden Ranking (2011). http://www.cwts.nl/ranking/LeidenRankingWebSite.html

Leimu, R. and Koricheva, J. (2005). Does scientific collaboration increase the impact of ecological articles? Bio Science, 55, 438-443.

Levitt, J.M. and Thelwall, M. (2010). Does the higher citation of collaborative research differ from region to region? A case study of Economics. Scientometrics, 85, 171-183.

Liao, H.C. (2011). How to improve research quality? Examining the impacts of collaboration intensity and member diversity in collaboration networks. Scientometrics, 86(3), 747-761. doi: 10.1007/s11192-010-0309-2

Narin, F., Stevens, K., Whitlow, E.S. (1991). Scientific cooperation in Europe and the citation of multinationally authored papers. Scientometrics, 21(3), 313-323.

Ortega, J. L. (2011). Collaboration patterns in patent networks and their relationship with the transfer of technology: the case study of the CSIC patent. Scientometrics, doi: 10.1007/s11192-011-03634

Persson, O. (2010). Are highly cited papers more international? Scientometrics, 83(2), 397-401.

Persson, O., Glänzel, W., Danell, R. (2004). Inflationary bibliometric values: The role of scientific collaboration and the need for relative indicators in evaluative studies. Scientometrics,, 60 (3): 421-432.

SCImago Research Group (2009). SIR - SCImago Institutions Rankings. http://www.scimagoir.com [February, 2011]

Sooryamoorthy, R. (2009). Collaboration and publication: How collaborative are scientists in South Africa? Scientometrics, 80(2), 419-439.

Van Leeuwen, T. N., \& Tijssen, R. J. W. (2007). Strength and weakness of national science systems. A bibliometric analysis through cooperation patterns. Scientometrics, 79(2), 389-408. 
Annex 1. Universities

\begin{tabular}{|c|c|c|}
\hline REGIONS & UNIVERSITIES & Abbreviations \\
\hline Northern America & $\begin{array}{l}\text { Harvard University } \\
\text { Massachusetts Institute of Technology } \\
\text { Stanford University } \\
\text { University of California, San Francisco } \\
\text { Boston University } \\
\text { University of California, Berkeley } \\
\text { University of Chicago } \\
\text { Columbia University } \\
\text { Johns Hopkins University } \\
\text { University of California, Los Angeles }\end{array}$ & $\begin{array}{l}\text { Harvard U. } \\
\text { MIT } \\
\text { Stanford U } \\
\text { UCAL SF } \\
\text { Boston U } \\
\text { UCAL Berkeley } \\
\text { U Chicago } \\
\text { Columbia U } \\
\text { Jhopkins U } \\
\text { UCAL LA }\end{array}$ \\
\hline Western Europe & $\begin{array}{l}\text { Erasmus University } \\
\text { University of Oxford } \\
\text { University of Cambridge } \\
\text { Swiss Federal Institute of Technology } \\
\text { Imperial College London } \\
\text { University College London } \\
\text { Unviersity of Glasgow } \\
\text { Utrecht University } \\
\text { Free University } \\
\text { University of Amsterdam }\end{array}$ & $\begin{array}{l}\text { Erasmus U } \\
\text { U Oxford } \\
\text { U Cambridge } \\
\text { ETH Zurich } \\
\text { IC London } \\
\text { UCol London } \\
\text { U Glasgow } \\
\text { Utrecht U } \\
\text { Free U } \\
\text { U Amsterdam }\end{array}$ \\
\hline Asiatic Region & $\begin{array}{l}\text { The University of Hong Kong } \\
\text { National University of Singapore } \\
\text { The Chinese University of Hong Kong } \\
\text { City University of Hong Kong } \\
\text { Nanyang Technological University } \\
\text { University of Tokyo } \\
\text { Hong Kong Polytecnic University } \\
\text { National Taiwan University } \\
\text { Korea advanced institute of science and technology } \\
\text { Kyoto University }\end{array}$ & $\begin{array}{l}\text { U HongKong } \\
\text { UN Singapore } \\
\text { Chinese U HK } \\
\text { City U HK } \\
\text { Nanyang Tech } \\
\text { U Tokyo } \\
\text { HK Pol } \\
\text { Nat Taiwan U } \\
\text { Korea Ad } \\
\text { Kyoto U }\end{array}$ \\
\hline Latin America & $\begin{array}{l}\text { Pontificia Universidad Catolica de Chile } \\
\text { Universidad de la Republica } \\
\text { Universidad de Buenos Aires } \\
\text { Universidade Federal de Pelotas } \\
\text { Universidad de Puerto Rico } \\
\text { Universidad de Chile } \\
\text { Universidad de Concepcion } \\
\text { Universidad Nacional de Mar del Plata } \\
\text { Pontificia Universidade Catolica do Rio de Janeiro } \\
\text { Universidad Nacional de Cordoba }\end{array}$ & $\begin{array}{l}\text { PUCat Chile } \\
\text { U Republica } \\
\text { U Baires } \\
\text { U Fed Pelotas } \\
\text { U Puerto Rico } \\
\text { U Chile } \\
\text { U Concepcion } \\
\text { UN Mar Plata } \\
\text { PU Rjaneiro } \\
\text { UN Cordoba }\end{array}$ \\
\hline
\end{tabular}


Annex 2. General Results

\begin{tabular}{|c|c|c|c|c|c|c|c|c|}
\hline Name Abbrev. & $\begin{array}{c}\text { \%_coll } \\
\text { int }\end{array}$ & $\begin{array}{l}\text { NI_coll } \\
\text { int }\end{array}$ & $\begin{array}{l}\% \text { \%_coll } \\
\text { int_n } \\
\text { at }\end{array}$ & \begin{tabular}{|l|} 
NI_coll \\
int_n \\
at
\end{tabular} & $\begin{array}{c}\% \text { _coll } \\
\text { nat }\end{array}$ & $\begin{array}{c}\text { NI_coll } \\
\text { nat }\end{array}$ & \%_none & NI_none \\
\hline Harvard U. & 10,08 & 1,81 & 23,00 & 2,63 & 49,71 & 2,25 & 17,22 & 1,68 \\
\hline MIT & 17,21 & 1,78 & 15,23 & 2,53 & 29,49 & 2,44 & 38,08 & 1,87 \\
\hline Stanford U. & 13,77 & 1,82 & 13,87 & 2,79 & 35,18 & 2,31 & 37,18 & 1,79 \\
\hline UCal. S. Francisco & 11,40 & 1,70 & 13,82 & 3,28 & 39,06 & 2,21 & 35,05 & 1,47 \\
\hline Boston U. & 12,97 & 1,50 & 14,58 & 2,55 & 39,06 & 2,04 & 33,39 & 1,35 \\
\hline UCal. Berkeley & 15,57 & 1,66 & 17,95 & 2,38 & 32,95 & 2,13 & 33,53 & 1,66 \\
\hline U. Chicago & 11,03 & 1,51 & 15,64 & 3,08 & 34,88 & 1,96 & 38,45 & 1,41 \\
\hline Columbia U. & 12,65 & 1,66 & 14,57 & 2,79 & 35,14 & 2,00 & 37,64 & 1,44 \\
\hline J. Hopkins U. & 12,57 & 1,72 & 16,75 & 2,71 & 38,59 & 1,93 & 32,10 & 1,37 \\
\hline UCal. LA & 13,84 & 1,66 & 13,95 & 2,66 & 33,48 & 2,14 & 38,73 & 1,55 \\
\hline Erasmus U. & 26,42 & 2,55 & 10,57 & 2,70 & 25,21 & 1,62 & 37,80 & 1,25 \\
\hline U. Oxford & 32,48 & 1,74 & 17,55 & 2,35 & 17,29 & 1,76 & 32,69 & 1,38 \\
\hline U. Cambridge & 33,54 & 1,71 & 15,02 & 2,39 & 17,72 & 1,74 & 33,73 & 1,38 \\
\hline ETH Zurich & 42,23 & 1,78 & 14,37 & 1,83 & 11,67 & 1,58 & 31,74 & 1,64 \\
\hline Imp. Col. London & 29,68 & 1,75 & 17,05 & 2,52 & 22,23 & 1,54 & 30,88 & 1,34 \\
\hline U. Col. London & 25,41 & 1,83 & 18,18 & 2,27 & 25,71 & 1,58 & 30,71 & 1,27 \\
\hline U. Glasgow & 27,82 & 1,83 & 14,75 & 2,63 & 21,80 & 1,56 & 35,64 & 1,15 \\
\hline Utrecht U. & 27,51 & 1,70 & 12,47 & 2,24 & 25,28 & 1,62 & 34,75 & 1,23 \\
\hline Free U. & 30,53 & 1,88 & 12,05 & 2,08 & 25,46 & 1,49 & 31,97 & 1,23 \\
\hline U. Amsterdam & 29,52 & 1,89 & 11,85 & 2,22 & 23,57 & 1,45 & 35,07 & 1,24 \\
\hline U. Hong Kong & 41,66 & 1,46 & 9,22 & 1,80 & 16,45 & 1,37 & 32,68 & 1,08 \\
\hline N. U. Singapore & 31,06 & 1,41 & 11,47 & 1,66 & 19,35 & 1,29 & 38,13 & 1,22 \\
\hline Chinese U. Hong Kd & 37,29 & 1,37 & 8,91 & 1,81 & 19,97 & 1,26 & 33,84 & 0,99 \\
\hline City U. Hong Kong & 57,68 & 1,33 & 4,67 & 1,65 & 6,28 & 1,10 & 31,38 & 1,08 \\
\hline Nanyang Tech. U. & 30,62 & 1,29 & 5,44 & 1,49 & 15,08 & 1,10 & 48,86 & 1,05 \\
\hline U. Tokio & 13,09 & 1,42 & 12,51 & 1,61 & 39,26 & 1,09 & 35,15 & 0,88 \\
\hline Hong Kong Pol. U. & 49,71 & 1,10 & 4,00 & 1,27 & 5,87 & 1,06 & 40,42 & 1,01 \\
\hline Nat. Taiwan U. & 12,25 & 1,40 & 7,93 & 1,54 & 39,17 & 0,96 & 40,65 & 1,01 \\
\hline Korea Ad. Inst sci\& & 14,52 & 1,42 & 5,48 & 1,16 & 26,84 & 0,95 & 53,17 & 1,07 \\
\hline Kyoto U. & 13,28 & 1,32 & 10,44 & 1,59 & 34,22 & 1,03 & 42,06 & 0,92 \\
\hline P. U. Cat. Chile & 31,22 & 1,36 & 12,16 & 1,38 & 17,89 & 0,71 & 38,72 & 0,60 \\
\hline U. de la Republica & 58,48 & 1,06 & 5,85 & 1,13 & 5,50 & 0,59 & 30,17 & 0,56 \\
\hline U. Buenos Aires & 25,45 & 1,29 & 14,97 & 1,15 & 28,31 & 0,58 & 31,27 & 0,53 \\
\hline U. Fed. Pelotas & 13,54 & 2,62 & 10,75 & 1,75 & 48,28 & 0,57 & 27,44 & 0,62 \\
\hline U. Puerto Rico & 51,57 & 1,14 & 2,87 & 1,00 & 1,98 & 0,93 & 43,59 & 0,49 \\
\hline U. Chile & 33,98 & 1,11 & 12,12 & 1,14 & 19,67 & 0,57 & 34,23 & 0,70 \\
\hline U. Concepcion & 40,21 & 1,07 & 12,52 & 1,10 & 18,19 & 0,63 & 29,09 & 0,53 \\
\hline U. N. Mar del Plata & 17,01 & 0,97 & 19,03 & 1,13 & 42,87 & 0,72 & 20,75 & 0,60 \\
\hline Pont. U. Rio Janeir & 13,56 & 1,25 & 10,38 & 1,28 & 43,50 & 0,66 & 32,57 & 0,39 \\
\hline U. N. Cordoba & 24,56 & 0,97 & 13,43 & 1,03 & 24,34 & 0,60 & 37,67 & 0,53 \\
\hline
\end{tabular}

